\title{
Comparison of one week and two weeks of triple therapy for the eradication of Helicobacter pylori in a Sri Lankan population: a randomised, controlled study
}

\author{
HA de Silva ${ }^{1}$, J Hewavisenthi ${ }^{2}$, A Pathmeswaran ${ }^{3}$, AS Dassanayake ${ }^{4}$, NMM Navaratne $^{5}$, R Peiris $^{6}$ and \\ HJ de Silva ${ }^{7}$
}

(Index words: Clarithromycin, compliance, efficacy, tinidazole and omeprazole therapy)

\begin{abstract}
Introduction Resistance of Helicobacter pylori to antibiotics may be particularly high in parts of the tropics. Infection may prove difficult to eradicate in such situations, and there is some evidence of benefit in increasing the duration of treatment (triple therapy) from 1 week to 2 or 3 weeks.
\end{abstract}

Aim To assess the efficacy and tolerability of 1 week versus 2 weeks of triple therapy for eradication of $H$. pylori in a Sri Lankan population.
Methods Eighty two patients aged 18-70 years with gastritis or peptic ulcer and testing positive for $H$. pylori infection were randomly allocated to two treatment groups. Both groups received omeprazole $20 \mathrm{mg}$, clarithromycin $250 \mathrm{mg}$, and tinidazole $500 \mathrm{mg}$. Group A $(n=42)$ received the trial medication twice daily for 1 week and the Group B $(n=40)$ twice daily for 2 weeks. $H$. pylori eradication was defined as a negative ${ }^{14} \mathrm{C}$ labelled urea breath test at 2 weeks after completion of the therapy.

Results $H$. pylori infection was eradicated in 36 (85.7\%) patients in Group A and 36 (90\%) patients in Group B

${ }^{1}$ Senior Lecturer in Pharmacology, ${ }^{2}$ Senior Lecturer in Pathology, ${ }^{3}$ Senior Lecturer in Community Medicine, ${ }^{4}$ Senior Lecturer in Pharmacology, ${ }^{5}$ Senior Registrar in Medicine, ${ }^{6}$ Senior Registrar in Medicine, ${ }^{7}$ Professor of Medicine, Faculty of Medicine, University of Kelaniya, and University Medical Unit, Colombo North Teaching Hospital, Ragama, Sri Lanka. Correspondence: H J de S, e-mail:<hjdes@sltnet.lk> (Competing interests: this study was funded by Ranbaxy Laboratories Ltd., India). Received 13 July 2004 and accepted 16 August 2004. 
$(p=0.9)$. Twenty three (55\%) patients in Group A and 17 $(43 \%)$ in Group B reported adverse effects attributable to trial medication ( $p=0.387$ ); none were serious. Three $(7.5 \%)$ patients in Group B discontinued treatment due to adverse events that developed on days 7, 9 and 10 .

Conclusion Twice daily treatment with clarithromycin, tinidazole, and omeprazole for 1 week is well tolerated and provides as good a rate of $H$. pylori eradication as 2week therapy in Sri Lankan patients.

\section{Introduction}

The pathogenic role of $H$. pylori in chronic active gastritis and its association with peptic ulcer disease are well established [1]. There is also evidence that $H$. pylori carriers are at an increased risk of developing gastric adenocarcinoma and lymphoma [1]. Eradication of infection with antimicrobial treatment heals peptic ulcers and substantially reduces the risk of their recurrence [2], and causes regression or resolution of gastric mucosaassociated lymphoid tissue, lymphomas [3, 4].

Eradication of $H$. pylori requires treatment with multiple drugs, most often two antimicrobial drugs supplemented with a proton pump inhibitor - triple therapy, usually for 1 week $[5,6]$. In Sri Lanka, triple therapy is widely used. A large meta-analysis of 666 studies involving more than 50000 patients [7] found no differences in eradication rates with different proton pump inhibitors (omeprazole, lansoprazole or panteprozole) or nitroimidazole antibiotics (metronidazole or tinidazole). Of the macrolide antibiotics evaluated, clarithromycin was superior to others in the group [7]. However, partial or complete resistance to antibiotics is an important factor that affects $H$. pylori eradication, and this may be particularly high in parts of the tropics $[8,9]$. Infection may prove difficult to eradicate in such situations, and there is some evidence of benefit in increasing the duration of treatment $[7,8]$. Indeed, two studies from India have shown that the eradication rates increase from about $50 \%$ with 1 -week treatment to over $90 \%$ with 2 - or 3-week treatment regimens $[10,11]$.

In this randomised, controlled trial, we assessed the efficacy and tolerability of 1 -week triple therapy with clarithromycin, tinidazole, and omeprazole against triple therapy with same drugs for 2 weeks in a Sri Lankan population.

\section{Methods}

\section{Patients}

Patients were recruited from the medical and surgical out-patient clinics and wards of the North Colombo Teaching Hospital, Ragama. Consecutive patients aged 18-70 years with clinical and endoscopic diagnosis of gastritis or peptic ulcer disease and testing positive for H. pylori infection were included in the study. The presence of $H$. pylori infection was demonstrated by histology on gastric antral biopsies in all trial patients (combination of haematoxyline and eosin and toluidine blue stains). A rapid urease test (CLOtest_-Bollard Medical Products, USA) was also performed. The histological examination was conducted by the same pathologist $(\mathrm{JH})$ throughout the study.

Those who did not fulfill all inclusion criteria, had contraindication(s) to any trial medication, were suffering from chronic debilitating diseases (e.g. malignancy, diabetes mellitus, heart failure), and chronic alcohol abusers, patients on nonsteroidal anti-inflammatory drugs, pregnant or nursing women, and those who had used any of the trial medications during the preceding 2 weeks, were excluded from the study.

Patients were given verbal and written information about the nature, objectives, importance and expected benefits of the trial. They were told that they were free to withdraw from the study at any time if they wished, without any prejudice to subsequent management. Written informed consent was obtained in Sinhalese or Tamil. The Ethics Committee of the Faculty of Medicine, University of Kelaniya approved the study.

Patients included in the study were randomised by using a computer generated random allocation table into two groups (Group A and B). Both the groups received triple therapy, which consisted of omeprazole $20 \mathrm{mg}$, clarithromycin $250 \mathrm{mg}$, and tinidazole $500 \mathrm{mg}$ (Pylobact $^{\mathrm{R}}$ - Ranbaxy Laboratories Ltd., India). Group A received the trial medication twice daily for 1 week and the Group B received the trial medication twice daily for 2 weeks. Patients were asked to swallow all capsules and tablets whole and take the medication at the same time each day to improve compliance. They were asked to return any remaining trial medications when they returned for assessment of $H$. pylori eradication after completion of the treatment. Intake of less than $75 \%$ of the prescribed number of tablets and capsules was considered as unsatisfactory compliance. Patients were also informed about the possible adverse effects of the treatment and were advised to report any adverse events to the treatment. These were recorded by the trial physicians at follow up.

\section{Assessment of patients}

All patients returned for clinical assessment and pill counting 2 weeks after the conclusion of therapy. During this visit they were questioned about relief of symptoms and development of adverse events to treatment. Eradication of $H$. pylori, the primary efficacy variable of the study, was assessed by ${ }^{14} \mathrm{C}$ labelled urea breath test (PYtest-Bollard Medical Products, USA) in all patients during this visit. H. pylori eradication was defined as negative ${ }^{14} \mathrm{C}$ labelled urea breath test at 2 weeks after the completion of the therapy. The assessors were blind to the randomisation and other information regarding patients. 


\section{Statistical analysis}

We expected the 2-week treatment to increase the eradication rate from $60 \%$ to $90 \%$. Thus we calculated that a sample size of 76 was needed to give the study $80 \%$ power at $\alpha=0.05$. We used SPSS (version 10) and did Fisher's exact test to assess differences between proportions and evaluate confidence intervals using CIA (version 2.0.5.46). Analysis was by intention to treat.

\section{Results}

The study was conducted from October 2001 to June 2003. During this period 82 patients, who fulfilled the inclusion criteria, were randomly allocated to the treatment groups as described above; Group A $n=42$, Group B $n=40$. None of the patients dropped out from the study and all came for follow up after completion of therapy. Baseline characteristics are shown in Table 1.

Table 1. Patients' baseline characteristics

\begin{tabular}{lcc}
\hline & $\begin{array}{c}\text { Therapy for } \\
1 \text { week } \\
(n=42)\end{array}$ & $\begin{array}{c}\text { Therapy for } \\
2 \text { weeks } \\
(n=40)\end{array}$ \\
\hline $\begin{array}{l}\text { Male sex (\%) } \\
\text { Age, mean years (SD) }\end{array}$ & $50.7(14.2)$ & $23(57.5)$ \\
Baseline tests & & $49.7(14.9)$ \\
CLO test + ve (\%) & $13(31.0)$ & $11(27.5)$ \\
Histology $+\mathrm{ve}(\%)$ & $42(100)$ & $40(100)$ \\
\hline
\end{tabular}

Thirty six $(85.7 \%$; 95\% CI 72.2-93.3) patients in the 1-week treatment group (Group A) and 36 (90\%; 95\% CI 76.9-96) patients in the 2-week treatment group (Group B) had negative ${ }^{14} \mathrm{C}$ labelled urea breath tests at the end of the treatment. These patients were considered as cured of $H$. pylori infection. The difference $(4.3 \%)$ was not statistically significant $(p=0.9)$. The $95 \%$ confidence intervals for the two groups overlapped to a great extent.

\section{Adverse effects}

Twenty three (55\%) patients in Group A and 17 (43\%) patients in Group B reported adverse effects attributable to the medication. The difference in incidence of adverse effects in the two groups was not significant $(p=0.387)$. No serious adverse events were reported. The most common adverse event was abnormal or bitter taste sensation in the mouth. Others were nausea, vomiting, diarrhoea, headache, dizziness, increased thirst, dry mouth, and body aches. Three $(7.5 \%)$ patients in Group B discontinued treatment because of adverse events that developed on days 7, 9 and 10. None in Group A discontinued treatment. Satisfactory compliance, defined as more than $75 \%$ of the prescribed drug intake, was noted in all patients except the three patients in Group B who discontinued treatment due adverse events.

\section{Discussion}

We report the results of a controlled trial, which assessed the efficacy and safety of 1 week versus 2 weeks of treatment with clarithromycin, tinidazole, and omeprazole (triple therapy) to eradicate H. pylori in Sri Lankan patients presenting with gastritis or peptic ulcer disease. The study shows that increasing the duration of treatment from 1 to 2 weeks does not result in a significantly higher rate of $H$. pylori eradication.

Our eradication rate of about $86 \%$ with 1 -week treatment using a combination of two antibiotics and a proton pump inhibitor compares favourably with results from other studies which used similar 1-week regimens from Europe [12, 13], China [14], Turkey [15] and USA [16]. In these studies too, the rates of $H$. pylori eradication were not significantly higher with prolonged treatment compared to treatment for 1 week. In contrast, triple therapy regimens for 1 week in India have yielded low eradication rates ranging from $47 \%$ to $54 \%[10,11]$. This may be due to high level of resistance to nitroimidazole antibiotics, particularly metronidazole, reported from India $[8,9]$. In the meta-analysis of 666 studies [7], it was shown that apart from different therapeutic regimens used, the only factor responsible for significant differences in cure rates was the nationality of the study population [7]. This finding suggests that epidemiological characteristics of patients and of $H$. pylori strains, principally antibiotic resistance, may be critical in determining the eradication rate in a specific population. A 1-week twice daily dose of a proton pump inhibitor and two antibiotics among clarithromycin, nitroimidazole, or amoxycillin is recommended in the UK and European guidelines [6]. Our study shows that similar recommendations may hold true for Sri Lanka as well.

Patient non-compliance to treatment is another factor associated with poor $H$. pylori eradication rates $[6,7]$. Eradication rates were lower in patients experiencing acute adverse events, seen more commonly in those receiving triple therapy for a duration longer than 1 week [17]. Although no serious adverse events attributable to the drugs used were reported during our trial, three patients in the group which received therapy for 2 weeks developed adverse events after 7-10 days of treatment, sufficiently distressing to warrant discontinuation of treatment. None in the 1-week treatment group discontinued therapy. Furthermore, 1 week of treatment halves the cost of therapy.

Demonstration of the organism by histology is now considered the gold standard for diagnosis of infection [18], particularly when the facilities for culture are either not freely available or not fully standardised. The rapid urease test seems to have a $95 \%$ sensitivity and specificity approaching $100 \%$ compared to the gold standards of histological examination or culture [18], and is the recommended test to detect $H$. Pylori in clinical trial settings $[6,19]$. However, there is a limitation to the use of urease testing in patients taking proton pump inhibitors, 
high-dose $\mathrm{H}_{2}$-receptor antagonists, or antimicrobials, which might decrease $H$. pylori density and consequently urease activity, thereby producing a false negative result $[18,20]$. Like in our study, high false negative rates have also been reported from India [21]. Widespread use of gastric acid suppressants and antimicrobials may be a reason. The ${ }^{14} \mathrm{C}$ labelled urea breath test is considered the first-line post-treatment diagnostic test [6]. Here too there is a potential for false negatives in individuals receiving acid suppressant drugs, antimicrobials, or bismuthcontaining compounds $[18,20]$. In order to overcome this confounding factor we performed the ${ }^{14} \mathrm{C}$ labelled urea breath tests on our patients 2 weeks after the completion of the therapy.

No therapeutic regime has achieved $100 \%$ efficacy for $H$. pylori infection. However, several regimens have been devised that attain eradication rates between $80 \%$ and $90 \%$. Therefore, an ideal H. pylori eradication treatment regime must be safe, cheap and tolerable, with more than an $80 \%$ eradication rate $[19,22]$. We conclude that twice daily treatment with clarithromycin, tinidazole, and omeprazole for 1 week is well tolerated and provides a good rate of $H$. pylori eradication in Sri Lankan patients. Increasing the duration of therapy may decrease compliance, without significant therapeutic benefit.

\section{Acknowledgements} funding.

We thank Ranbaxy Laboratories Ltd., India, for

\section{References}

1. Blaser MJ. Helicobacter pylori and gastric diseases. British Medical Journal 1998; 316: 1507-10.

2. Hentschel E, Brandstatter G, Dragoisics B, Hirschl AM, Nemec $\mathrm{H}$, et al. Effect of ranitidine and amoxicillin plus metronidazole on the eradication of Helicobacter pylori and the recurrence of duodenal ulcer. New England Journal of Medicine 1993; 328: 308-12.

3. Bayerdorffer E, Neubauer A, Rudolph B, Thiede C, Lehn $\mathrm{N}$, et al. Regression of primary gastric lymphoma of mucosa-associated lymphoid tissue type after cure of Helicobacter pylori infection. Lancet 1995; 345: 1591-4.

4. Fischbach W, Goebeler-Kolve ME, Dragosics B, Greiner A, Stolte M. Long term outcome of patients with gastric marginal zone B cell lymphoma of mucosa associated lymphoid tissue (MALT) following exclusive Helicobacter pylori eradication therapy: experience from a large prospective series. Gut 2004; 53: 34-7.

5. Bazzoli F, Zagari M, Pozzato P, Varoli O, Fossi S, et al. Evaluation of short-term low-dose triple therapy for the eradication of Helicobacter pylori by factorial design in a randomized double-blind controlled study. Alimentary Pharmacology and Therapeutics 1998; 12: 439-46.

6. Malfertheiner P, Megraud F, O' Morain C, Hungin AP, Jones R, et al. Current concepts in the management of
Helicobacter pylori infection-the Maastricht 2-2000 Consensus Report. Alimentary Pharmacology and Therapeutics 2002; 16: 167-80.

7. Laheij RJF, Van Rossum LGM, Jansen JBMJ, Straatman H, Verbeek ALM. Evaluation of treatment regimens to cure Helicobacter pylori infection - a meta analysis. Alimentary Pharmacology and Therapeutics 1999; 13: 857-64.

8. Sharma MP, Ahuja V. Peptic ulcer disease in the tropics: lessons from India. Ceylon Medical Journal 2000; 45: 103-6.

9. Abraham P, Sandhu N, Naik SR. In vitro sensitivity of Helicobacter pylori in India. Indian Journal of Gastroenterology 1997; 16 (suppl 1): S20-1.

10. Bhasin DK, Sharma BC, Ray P, Pathak CM, Singh K. Comparison of seven and fourteen days of lansoprazole, clarithromycin, and amoxicillin therapy for eradication of Helicobacter pylori: A report from India. Helicobacter 2000; 5: 84-7.

11. Chaudhary A, Ahuja V, Bal CS, Das B, Pandey RM, et al. Rank order of success favors longer duration of imidazole-based therapy for Helicobacter pylori in duodenal ulcer disease: a randomized pilot study. Helicobacter 2004; 9: 124-9.

12. Lind T, Veldhuyzen van Zanten S, Unge P, Spiller R, Bayerdorffer E, et al. Eradication of Helicobacter pylori using one-week triple therapies combining omeprazole with two antimicrobials: the MACH-1 study. Helicobacter 1996; 1: 138-44.

13. Misiewicz JJ, Harris AW, Bardhan KD, Levi S, O’Morain $\mathrm{C}$, et al. One week triple therapy for Helicobacter pylori: a multicentre comparative study. Gut 1997; 41: 735-9.

14. Guo C-Y, Wu Y-B, Liu H-L, Wu J-Y, Zhong M-Z. Clinical evaluation of four one-week triple therapy regimens in eradicating Helicobacter pylori infection. World Journal of Gastroenterology 2004; 10: 747-9.

15. Forne M, Viver JM, Esteve M, Fernandez-Banares F, Lite $\mathrm{J}$, et al. Randomized clinical trial comparing two one-week triple-therapy regimens for the eradication of Helicobacter pylori infection and duodenal ulcer healing. American Journal of Gastroenterology 1998; 93: 35-8.

16. Laine L, Estrada R, Trujillo M, Fukanaga K, Neil G. Randomized comparison of differing periods of twice-aday triple therapy for the eradication of Helicobacter pylori. Alimentary Pharmacology and Therapeutics 1996; 10: $1029-33$

17. Graham DY, Lew GM, Malaty HM, Evans DG, Evans D Jr., et al. Factors influencing eradication of Helicobacter pylori with triple therapy. Gastroenterology 1992; 102: 493-6.

18. Peterson WL, Fendrick M, Cave DR, Peura DA, Garabedian-Ruffalo SM, et al. Helicobacter pylori-related disease. Guidelines for testing and treatment. Archives of Internal Medicine 2000; 160: 1285-91.

19. Working party of the European Helicobacter pylori study group. Guidelines for clinical trials in Helicobacter pylori infection. Gut 1997; 41 (Suppl. 2): S1-9. 


\section{Papers}

20. Laine L, Estrada R, Trujillo M, Knigge K, Fennerty MB. Effect of proton pump inhibitor therapy on diagnostic testing for Helicobacter pylori. Annals of Internal Medicine 1998; 129: 547-50.

21. Kini D, Aggarawal R, Saraswat VA, Naik SR. Role of Helicobacter pylori infection in hyperammonemia and subclinical hepatic encephalopathy in cirrhosis of liver. Indian Journal of Gastroenterology 2001; 20: 237-40.

22. Soll AH. Consensus conference. Medical treatment of peptic ulcer disease. Practice guidelines. Practice Parameters Committee of the American College of Gastroenterology. Journal of the American Medical Association 1996; 275: 622-9. 